\title{
The use of Classical Rolling Pendulum Bearings (CRPB) for vibration control of stay-cables
}

\author{
Georgia Papastergiou, ${ }^{1, *}$, and Ioannis Raftoyiannis ${ }^{2}$ \\ ${ }^{1,2}$ National Technical University of Athens, Dept. of Civil Engineering, Greece
}

\begin{abstract}
Cables are efficient structural elements that are used in cable-stayed bridges, suspension bridges and other cable structures. A significant problem which arose from the praxis is the cables' rain-wind induced vibrations as these cables are subjected to environmental excitations. Rain-wind induced stay-cable vibrations may occur at different cable eigenfrequencies. Large amplitude Rain-Wind-Induced-Vibrations (RWIV) of stay cables are a challenging problem in the design of cable-stayed bridges. Several methods, including aerodynamic or structural means, have been investigated in order to control the vibrations of bridge's stay-cables. The present research focuses on the effectiveness of a movable anchorage system with a Classical Rolling Pendulum Bearing (CRPB) device. An analytical model of cable-damper system is developed based on the taut string representation of the cable. The gathered integral-differential equations are solved through the use of the Lagrange transformation. . Finally, a case study with realistic geometrical parameters is also presented to establish the validity of the proposed system.
\end{abstract}

\section{Introduction}

Cable-stayed (C-S) bridges have been known since the beginning of the 18th century, but there were difficulties in their static and dynamic analysis. A significant problem, which arose from the practice, is the cables rain-wind induced vibrations. Large amplitude RainWind-Induced-Vibrations (RWIV) of stay-cables constitutes a challenging problem in the design of C-S bridges. Several methods, have been investigated in order to control the vibrations of bridge's stay cables.

This paper investigates the effectiveness of a movable anchorage system with a Classical Rolling Pendulum Bearing (CRPB) device. An analytical model of the cable-damper system is developed herein based on the taut string representation of the cable. The gathered integral-differential equations are solved through the use of the Lagrange transformation. Finally, a case study with realistic geometrical parameters is also presented to establish the validity of the proposed system, while the required device for the studied case is designed (see Fig. $1)$.
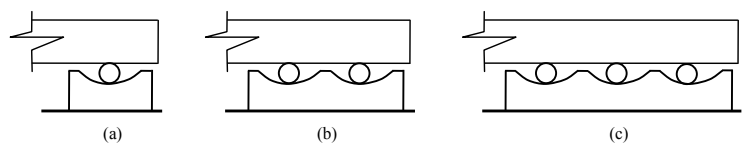

Fig. 1. Various forms of a CRPB with: (a) one, (b) two, and (c) three concaves

\section{Basic assumptions}

The deformed shape of the cables under dead and live loads is a catenary curve, with displacements wo and tensile forces To (see Fig.2), which because of its very shallow form can be approximated by a second-order parabola.

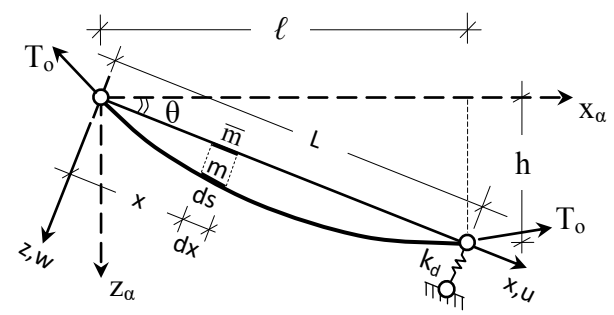

Fig. 2. Cable and reference axes

Under the action of the dynamic loads py $(x, t)$ and $\mathrm{pz}(\mathrm{x}, \mathrm{t})$, the cable takes the form of Fig. 3, with additional displacements $u_{d}, v_{d}, w_{d}$ and tensile forces $T_{d}$.

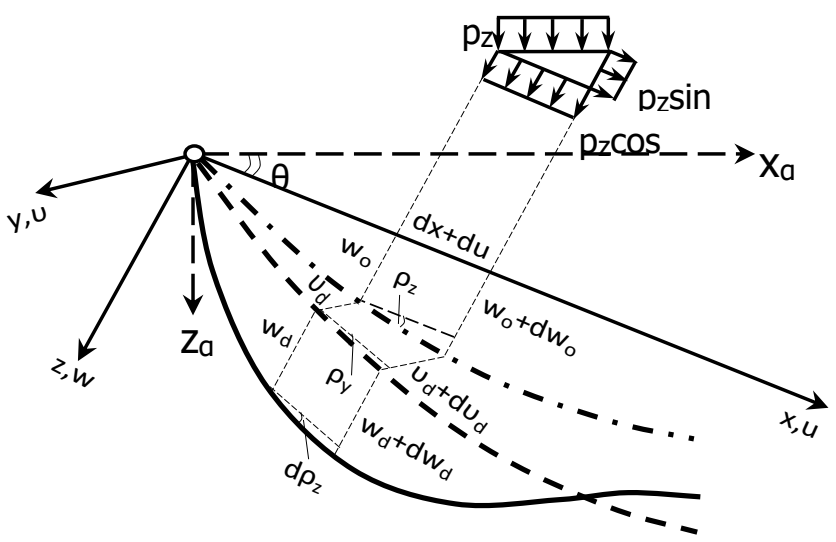

Fig. 3. Deformation of the cable

\footnotetext{
* Corresponding author: papastergiou.georgina@gmail.com
} 


\section{Equilibrium equations of a taut cable}

\subsection{Projection on xoz-plane}

\subsubsection{Equilibrium of horizontal forces}

Projecting on xoz-plane and taking the equilibrium of horizontal forces, we obtain:

$$
\frac{\partial H}{\partial s}-c \dot{u}-m \ddot{u}=-p_{x}(x, t)
$$

\subsubsection{Equilibrium of vertical forces}

Projecting on xoz-plane and taking the equilibrium of vertical forces, we obtain:

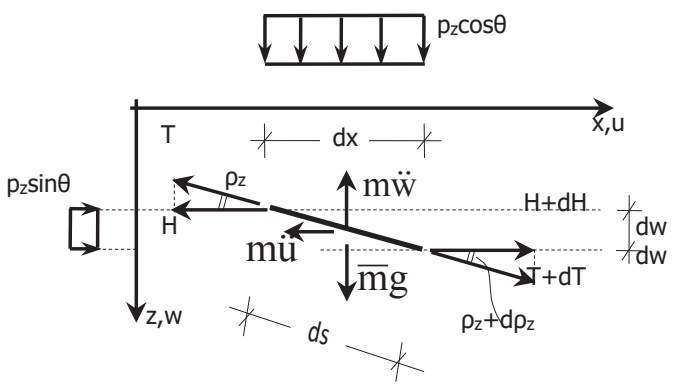

Fig. 4. Projection on xoz-plane

$T_{o} \frac{\partial^{2} w_{d}}{\partial x^{2}}+T_{d}\left(\frac{\partial^{2} w_{o}}{\partial x^{2}}+\frac{\partial^{2} w_{d}}{\partial x^{2}}\right)-c \dot{w}_{d}-m \ddot{w}_{d}=-p_{z}(x, t)$

\subsection{Projection on xoy-plane}

Projecting on xoy-plane, we obtain:

$$
\begin{aligned}
& T_{o} \frac{\partial^{2} v_{d}}{\partial x^{2}}+T_{d} \frac{\partial^{2} v_{d}}{\partial x^{2}}-c \dot{v}_{d}-m \ddot{v}_{d}=-p_{y}(x, t)
\end{aligned}
$$

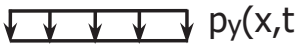

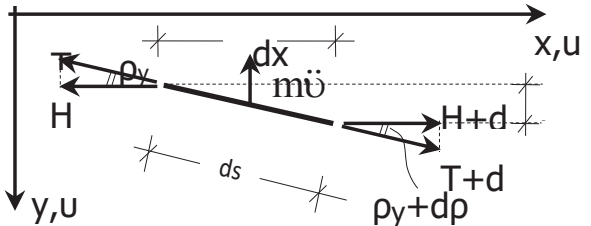

Fig. 5. Projection on xoy-plane

\subsection{The cables' deformation}

With boundary condition $w_{d}(0)=0$ we obtain: $T_{d}=\frac{1}{L_{o}}\left(w_{o}^{\prime}(L) w_{d}(L)-w_{o}^{\prime \prime} \int_{0}^{L} w_{d} d x\right)$ with : $L_{o}=\int_{0}^{L} \frac{d x}{E A \cos ^{3} \rho_{z}}$

\subsection{Catenary and the parabola approach}

It is usual to use the parabola as a curve that is very close to the catenary one, especially for shallow forms of cables. For a cable's shallow form the equation of a parabola passing from the points $(0,0),(\mathrm{L}, 0)$ and having $w_{o}^{\prime \prime}=-\frac{\bar{m} g}{H_{o}}$ is given by the following formula:

$$
w_{o}(x)=\frac{\bar{m} g}{2 H_{o}} \cdot x \cdot(L-x)
$$

\section{Analysis}

\subsection{The cable}

The stay-cable model with the considered anchoragebearing system is shown in Fig. 6 .

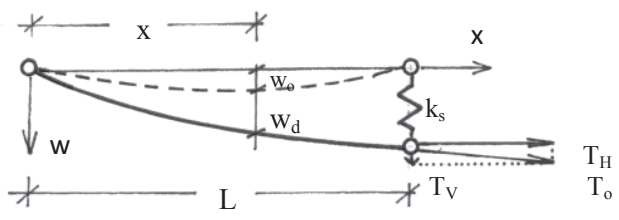

Fig. 6. The stay-cable model

\subsection{The rolling pendulum bearing system}

Let us consider a C.R.P.B. device with one concave rolling, like the one of Fig.7. The C.R.P.B. system is made from material like the one of the classical ballbearings having surfaces elaborated wery diligently, with coefficient of rolling friction ranging from 0.002 to 0.005 . Therefore, the developed friction forces can be neglected in this preliminary study. On the other hand, the angle of the friction cone amounts up to $0.34 \mathrm{o}$, which corresponds to a very small static friction.

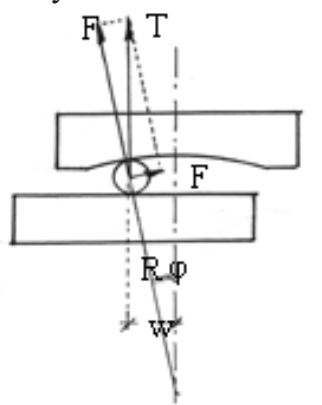

Fig. 7. Geometry of a C.R.P.B. system

\subsection{The equation of motion}

We obtain the following equation of motion:

$$
\begin{aligned}
& T_{o} w_{d}^{\prime \prime}+\frac{w_{o}^{\prime}(L) w_{d}(L)}{L_{o}} w_{o}^{\prime \prime}-\frac{w_{o}^{\prime \prime}}{L_{o}} \int_{0}^{L} w_{d} d x-c \dot{w}_{d}-m \ddot{w}_{d}=p(x, t)+\frac{T_{o}}{R} w_{d} \delta(x-L) \\
& \text { boundary conditions: } \quad w_{d}(0)=0, T_{o} w_{d}^{\prime}(L)+\frac{T_{o}}{R} w_{d}(L)=0
\end{aligned}
$$

\subsection{The free vibrating cable}

The equation of motion of a free vibrating cable with movable anchorage is:

$\mathrm{T}_{\mathrm{o}} \mathrm{w}_{\mathrm{d}}^{\prime \prime}-\mathrm{c} \dot{\mathrm{w}}_{\mathrm{d}}-\mathrm{m}_{\mathrm{d}}=-\frac{\mathrm{w}_{\mathrm{o}}^{\prime}(\mathrm{L}) \mathrm{w}_{\mathrm{d}}(\mathrm{L})}{\mathrm{L}_{\mathrm{o}}} \mathrm{w}_{\mathrm{o}}^{\prime \prime}+\frac{\mathrm{w}_{\mathrm{o}}^{\prime 2}}{\mathrm{~L}_{\mathrm{o}}} \int_{0}^{\mathrm{L}} \mathrm{w}_{\mathrm{d}} \mathrm{dx}$ 
We are searching for a solution of separated variables of the form:

$$
w_{d}(x, t)=W(x) \Phi(t)
$$

One can determine the following form of the shape functions:

$$
W_{n}(x)=c_{1}\left[\left(\sin \lambda_{n} x+D_{1}\right)+\frac{\lambda_{n} T_{o} \cos \lambda_{n} L+\frac{T_{o}}{R}\left(\sin \lambda_{n} L+D_{2}\right)}{\lambda_{n} T_{o} \sin \lambda_{n} L-\frac{T_{o}}{R}\left(\cos \lambda_{n} L+D_{2}\right)} \cdot\left(\cos \lambda_{n} x+D_{2}\right)\right]
$$

\subsection{The forced vibrating cable}

We are searching for a solution of the form:

$$
w_{d}(x, t)=\sum_{n} W_{n}(x) Z_{n}(t)
$$

and we conclude finally to: $Z_{k}(t)=L^{-1} \zeta_{k}(s)$

\section{Numerical results and discussion}

\subsection{The cables}

Let us consider a C-S bridge with dense distribution of cables from which we study a cable having tension $\mathrm{To}=300000 \mathrm{dN} /$ cable, cross-sectional area $\mathrm{F}=7.5 \cdot 10$ $3 \mathrm{~m} 2$, diameter $\mathrm{D}=0.13 \mathrm{~m}$, weight $\mathrm{G}=70 \mathrm{dN} / \mathrm{m}$, mass per unit length $m=7 \mathrm{~kg} / \mathrm{m}$, and variable length $\mathrm{L}=150,250$, and $350 \mathrm{~m}$.

\subsection{The rain-wind combination}

It has been observed that the rain-wind-induced vibration in bridge cables usually occurs in a frequency range from 0.5 to $4 \mathrm{sec}-1$. For the study of the vibration of a cable under the action of a rain-wind combination we choose the following loading: $p=p(x) \cdot f(t)=20 \cdot \sin \omega t$, where $\omega=1,2,3,4 \mathrm{sec}-1$ (for the study of the above cables without a damping system) and $\omega=3$ sec- 1 (for the study of the above cables with the proposed C.R.P.B. devise).

\subsection{Behavior of the cables without a damping system}

Table 1. Eigenfrequencies of the cables

\begin{tabular}{|l|c|c|c|}
\hline & $\mathrm{m}=7 \mathrm{~kg} / \mathrm{m}$, & $\mathrm{To}=300000 \mathrm{dN}$ \\
\hline & $\mathrm{L}=150 \mathrm{~m}$ & $\mathrm{~L}=250 \mathrm{~m}$ & $\mathrm{~L}=350 \mathrm{~m}$ \\
\hline$\omega_{1}$ & 4.4697 & 2.8186 & 2.1507 \\
\hline$\omega_{2}$ & 8.6716 & 5.2029 & 3.7164 \\
\hline$\omega_{3}$ & 13.0125 & 7.8130 & 5.5868 \\
\hline$\omega_{4}$ & 17.3432 & 10.4059 & 7.4328 \\
\hline$\omega_{5}$ & 21.6801 & 13.0093 & 9.2936 \\
\hline
\end{tabular}

In Figs 8 to 10, one can see the oscillations of the midlength of the studied cables with length $\mathrm{L}=150, \mathrm{~L}=250$ and $\mathrm{L}=350 \mathrm{~m}$, subjected to loadings acting with frequencies $\omega=1,2,3,4$ sec-1.

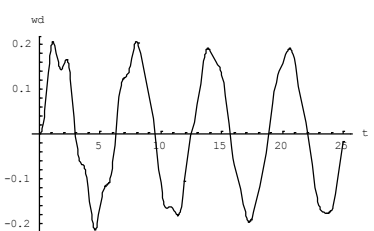

$\mathrm{p}=20 \cdot \operatorname{Sin}(1 \cdot \mathrm{t})$

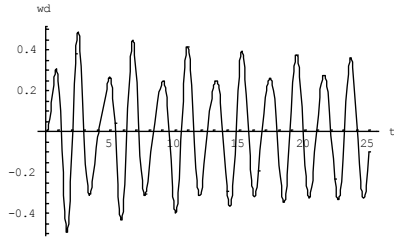

$\mathrm{p}=20 \cdot \operatorname{Sin}(3 \cdot \mathrm{t})$

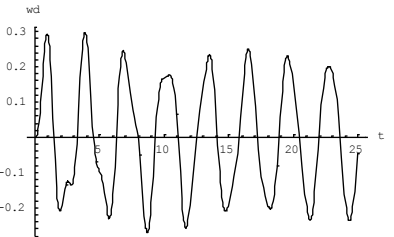

$\mathrm{p}=20 \cdot \operatorname{Sin}(2 \cdot \mathrm{t})$

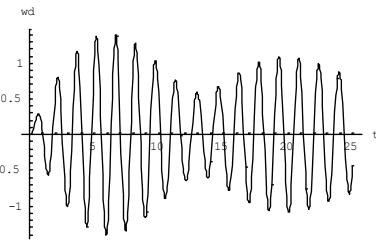

$p=20 \cdot \operatorname{Sin}(4 \cdot t)$
In this case, big deformations appear, because the eigenfrequency of the external load is near to the first one of the cable $(\omega 1=4.47 \mathrm{sec}-1)$

Fig. 8. Oscillations of the mid-length of a cable of length $\mathrm{L}=150 \mathrm{~m}$, without any damping system

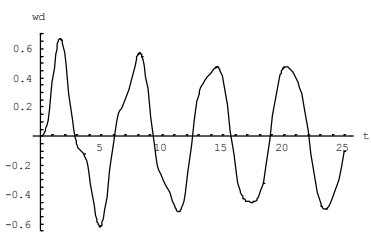

$\mathrm{p}=20 \cdot \operatorname{Sin}(1 \cdot \mathrm{t})$
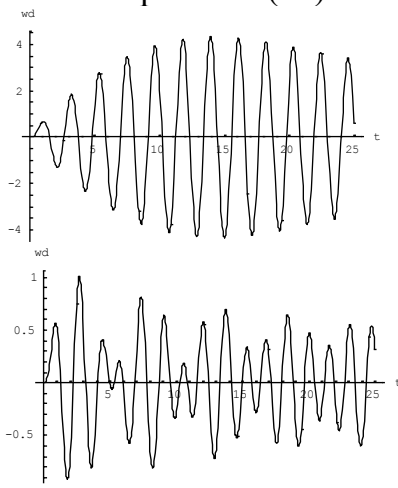

$p=20 \cdot \operatorname{Sin}(3 \cdot t)$
In this case, big deformations appear, because the eigenfrequency of the external load is near to the first one of the cable $(\omega 1=2.82 \mathrm{sec}-1)$.

Fig. 9. Oscillations of the mid-length of a cable of length $\mathrm{L}=250 \mathrm{~m}$, without any damping system

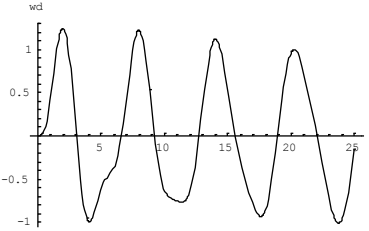

$p=20 \cdot \operatorname{Sin}(1 \cdot t)$

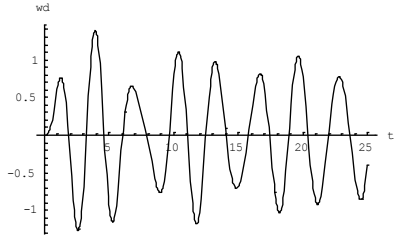

$\mathrm{p}=20 \cdot \operatorname{Sin}(2 \cdot \mathrm{t})$ $p=20 \cdot \operatorname{Sin}(4 \cdot t)$

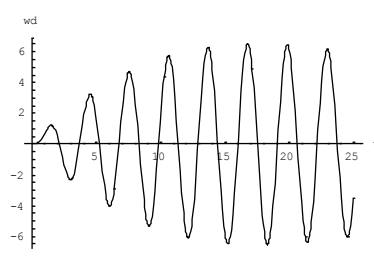

$p=20 \cdot \operatorname{Sin}(2 \cdot t)$ 
In this case, big deformations appear, because the eigenfrequency of the external load is near to the first one of the cable $(\omega 1=2.15$ sec- 1$)$.

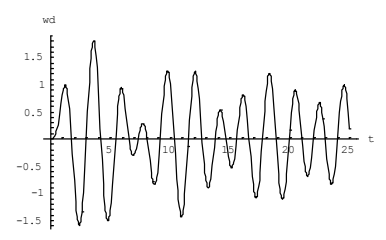

$\mathrm{p}=20 \cdot \operatorname{Sin}(3 \cdot \mathrm{t})$

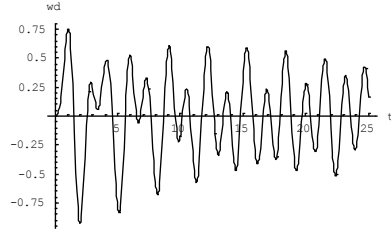

$\mathrm{p}=20 \cdot \operatorname{Sin}(4 \cdot \mathrm{t})$
Fig. 10. Oscillations of the mid-length of a cable of length $\mathrm{L}=350 \mathrm{~m}$, without any damping system

\subsection{The damping system}

In the followings, we will use a C.R.P.B. device, based on the operation principle of the simple system of Fig. 7. We will consider devices with concave radii $\mathrm{R}=1,2$, and 3 meters.

In the plots of Figs 12, 13, 14, we see the oscillations of the middle and of the anchor head of a cable of length $150 \mathrm{~m}$, tension $300000 \mathrm{dN}$, and for different values of $\mathrm{R}$.
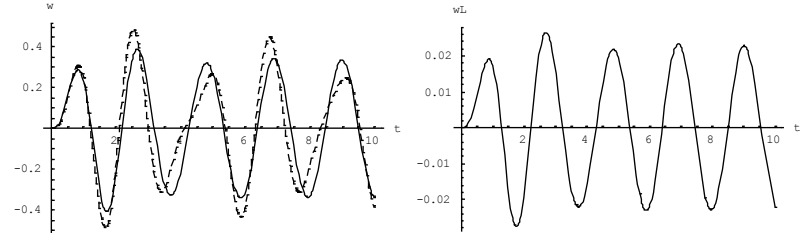

Fig. 11. Oscillations of the mid-length and of its anchor head of a cable of $\mathrm{L}=150 \mathrm{~m}, \mathrm{R}=3 \mathrm{~m}$ with , - - - without

C.R.P.B

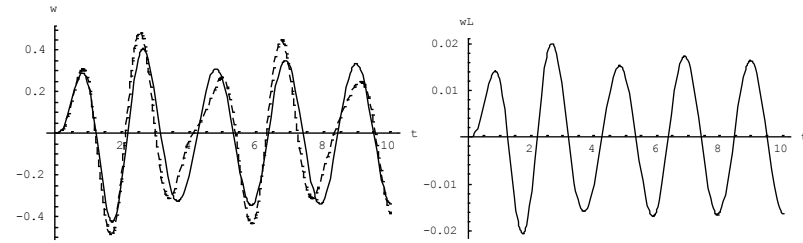

Fig. 12. Oscillations of the mid-length and of its anchor head of a cable of $\mathrm{L}=150 \mathrm{~m}, \mathrm{R}=2 \mathrm{~m}$ with , - - without C.R.P.B
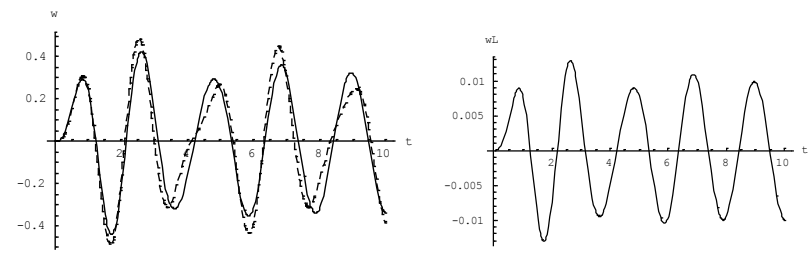

Fig. 13. Oscillations of the mid-length and of its anchor head of a cable of $\mathrm{L}=150 \mathrm{~m}, \mathrm{R}=1 \mathrm{~m}$ with,- - - without C.R.P.B

From the above plots of Figs 11 to 13 , we ascertain that smaller radii are more effective than the greater ones.
The above results are valid for both the cables' deformations and the anchorages' motion.

In the plots of Figs 14, 15, and 16, we see the oscillations of the mid-length and of the anchor head of a cable of length $250 \mathrm{~m}$, tension $300000 \mathrm{dN}$, and for different values of $\mathrm{R}$.

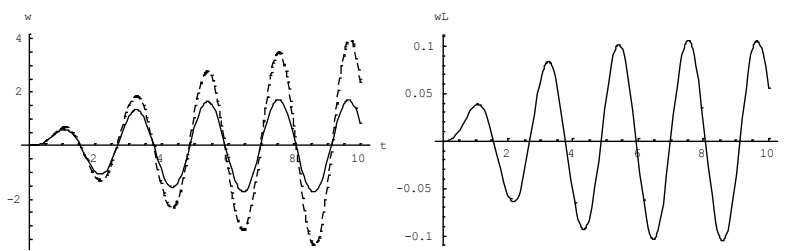

Fig. 14. Oscillations of the mid-length and of its anchor head of a cable of $\mathrm{L}=250 \mathrm{~m}, \mathrm{R}=3 \mathrm{~m}$ with, - - - without C.R.P.B

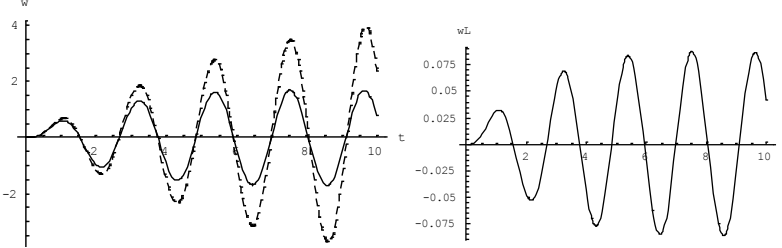

Fig. 15. Oscillations of the mid-length and of its anchor head of a cable of $\mathrm{L}=250 \mathrm{~m}, \mathrm{R}=2 \mathrm{~m}$ with, - - - without C.R.P.B

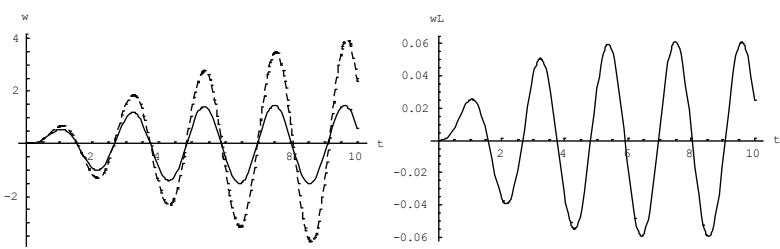

Fig. 16. Oscillations of the mid-length and of its anchor head of a cable of $\mathrm{L}=250 \mathrm{~m}, \mathrm{R}=1 \mathrm{~m}$ with, - - - without C.R.P.B

From the above plots of Figs 14 to 16, we observe that although the oscillations' amplitude is remarkable large the effectiveness of the system is obvious. We ascertain, again, that smaller radii are more effective than the greater ones. The above results are valid for both the cables' deformations and the anchorages' motion.

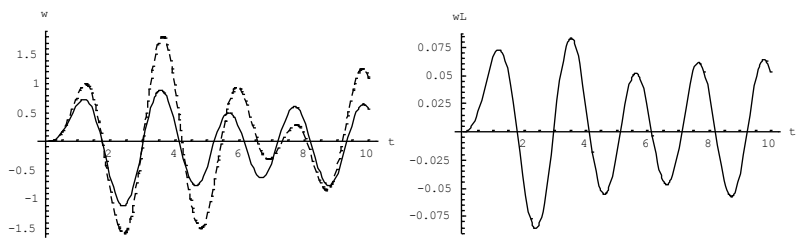

Fig. 17. Oscillations of the mid-length and of its anchor head of a cable of $\mathrm{L}=350 \mathrm{~m}, \mathrm{R}=3 \mathrm{~m}$ with, - - - without C.R.P.B

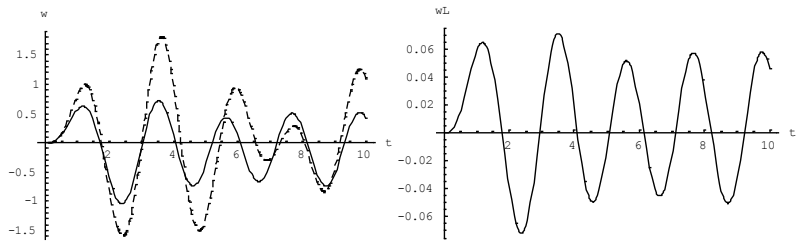


Fig. 18. Oscillations of the mid-length and of its anchor head of a cable of $\mathrm{L}=350 \mathrm{~m}, \mathrm{R}=2 \mathrm{~m}$ with, - - - without C.R.P.B
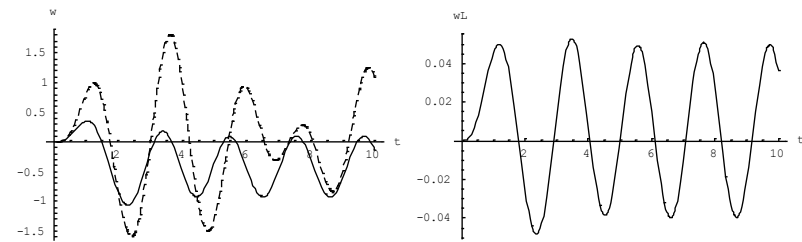

Fig. 19. Oscillations of the mid-length and of its anchor head of a cable of $\mathrm{L}=350 \mathrm{~m}, \mathrm{R}=1 \mathrm{~m}$ with, - - - without C.R.P.B

In the plots of Figs 17, 18, and 19, we see the oscillations of the mid-length and of the anchor head of a cable with length $350 \mathrm{~m}$, tension $300000 \mathrm{dN}$, and for different values of $\mathrm{R}$.

From the above plots of Figs 17 to 19, we ascertain, once again, that smaller radii are more effective than the greater ones. The above results are valid for both the cables' deformations and the anchorages' motion.

\section{Design of a C.R.P.B. device}

\subsection{Bearing capability}

Manufactures of ball bearings typically publish "LOAD RATINGS" for each bearing that they produce. Both ABMA and ISO have published standards related to load ratings. ABMA std. 9 - Load Ratings and Fatigue life for Ball Bearings. ABMA std. 12.1 and 12.2 Instrument Ball Bearings. ISO 76 - Static Load Ratings. ISO 281- Dynamic Load Ratings and Rating Life. Static load ratings and dynamic load ratings are calculated on completely different ways and there is not direct relationship to one another. The Basic Static Load Rating applies to bearings where motion does not occur or occurs only infrequently. The basic load ratings and calculation methods are based on methods described by the above-mentioned ISO recommendations.

As a standard of permissible static load, the basic load rating is specified as follows: Maximum contact pressure at the contact point $4200 \mathrm{MPa}(1 \mathrm{MPa}=100 \mathrm{~N} / \mathrm{cm} 2)$

Total permanent deformation of the compressed zone can be, approximately, 1/10000th of the rolling elementary diameter. The basic load rating for stainless steel is $80 \%$ of that for standard bearing steel.

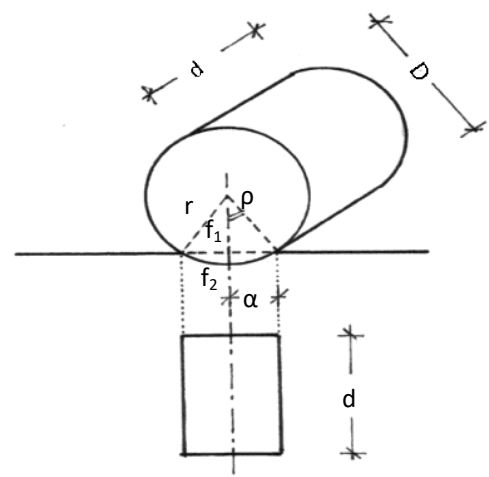

Fig. 20. Geometry of a cylinder bearing

According to the above recommendations, one can proceed as follows (see Fig. 20):

$\mathrm{f}_{2}=\frac{2 \mathrm{r}}{10000}=\mathrm{r} \cdot 2 \cdot 10^{-4}$ and $\mathrm{f}_{1}=\mathrm{r}-\mathrm{f}_{2}=0.9998 \cdot \mathrm{r}$

From the above, we find: $\cos \rho=\frac{f_{1}}{r}=0.9998=$ constan $t$ or finally:

$\rho=0.020 \operatorname{rad}\left(\sim 1.146^{\circ}\right)=$ cons $\tan \mathrm{t}$

From the sketch of Fig. 20, we get: $\quad \alpha \cong 2 \pi \mathrm{r} \frac{\rho}{2 \pi}=\rho \mathrm{r}$
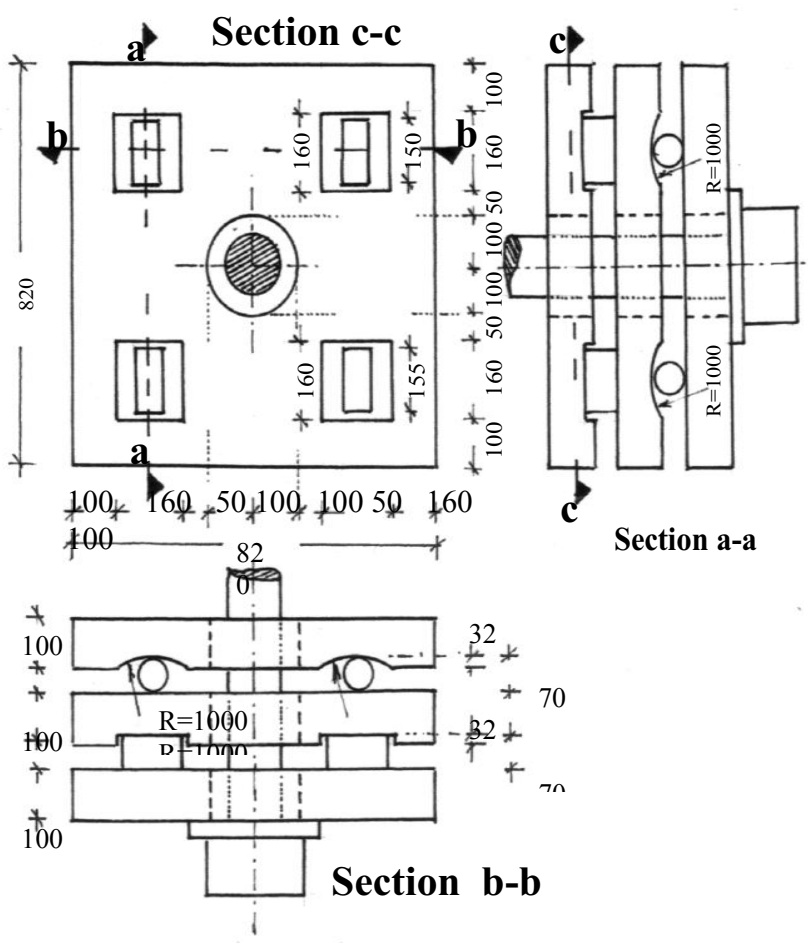

Fig. 21. The required C.R.P.B.

Therefore, for the safe undertaking of a load To, the required length $\mathrm{d}$ of the cylinder of Fig. 21, can be determined by the following relations:

$\mathrm{d}=\frac{\mathrm{T}_{\mathrm{o}}}{2 \alpha \sigma_{\mathrm{per}}}, \quad$ or for stainless steel $: \mathrm{d}=\frac{1.25 \cdot \mathrm{T}_{\mathrm{o}}}{2 \alpha \sigma_{\mathrm{per}}}$

\subsection{Selection of the appropriate C.R.P.B.}

We select a device with $\mathrm{R}=1 \mathrm{~m}$, and $\mathrm{D}=2 \mathrm{r}=7 \mathrm{~cm}$.

From $\S 6.1$, we have $\alpha=\rho \mathrm{r}=0.020 \cdot 3.5=0.07 \mathrm{~cm}$ and $\mathrm{d}=\frac{\mathrm{T}_{\mathrm{o}}}{2 \alpha \sigma_{\text {per }}}=\frac{300000}{2 \cdot 0.07 \cdot 42000}=51 \mathrm{~cm}$ or, equivalently, 4 
The designed C.R.P.B. device shown in Fig. 22 can undertake loads acting to any direction because the rolling cylinders operate along two perpendicular axes.

\section{Conclusions}

In this paper, a movable anchorage system with Classical Rolling Pendulum Bearing (C.R.P.B.) for vibration control of stay cables has been proposed and investigated. A model for the control system has been formulated, based on the taut string representation in which the proposed device has been incorporated.

From the studied cases, one can conclude to the followings:

a) The constant of the equivalent spring of the CRPB system has been assessed.

b) The results of cable response show that the proposed CRPB device can effectively reduce the oscillation magnitude of the cable, proving the efficiency of the system.

c) The observed decrease of the cable's oscillations amounts from $15 \%$ to $50 \%$, while the motion of the anchor-head of the selected and designed device amounts from 1.5 to $6 \mathrm{~cm}$. One must note that the CRPB device is very effective even for external loads acting with frequencies equal or near to one of the eigenfrequencies of the strained cable.

d) The design parameters of the CRPB system for the selected cables are identified and the proper device has been designed.

e) The proposed anchorage system is shown to perform more efficiently than the conventional passive external dampers, presenting a better solution from aesthetics point of view.

\section{References}

[1] J.F. Fleming, "Non-linear static analysis of cablestayed bridge structures", Comp. Struct., (1979), 10, pp. 986-1000

[2] C.F. Kollbruner, N. Hajdin, and B. Stipanic, "Contribution to the analysis of cable-stayed Bridges", Inst. For Engineering Research Editions, (1980), N. 48, Schulthess Verlag, Zürich

[3] M.S. Khalil, "Non-linear analysis of cable-stayed bridges at ultimate load level", Canadian J. of Civil Engineering, (1999), 23 (5), pp. 1111-1117

[4] G.T Michaltsos, J.C. Ermopoulos, and T.G. Konstantakopoulos, "Preliminary design of cable-stayed bridges for vertical static loads", J. of Structural Engineering and Mechanics, (2003), 16(1), pp. 1-15

[5] J.F. Fleming, and E.A. Egeseli, "Dynamic behavior of a cable-stayed bridge", Int. Journal of Earthquake Eng. \& Structural Dynamics, (1980), 8(1), pp. 1-16

[6] D. Bruno, and V. Colotti, "Vibration analysis of cable-stayed bridges", Journal of Structures Ing. International, (1994), 1, pp. 23-28

[7] G.T. Michaltsos, "A simplified model for the dynamic analysis of cable-stayed bridges", Facta Universitatis, (2001), 3(11), pp. 185-204
[8] T.G. Konstantakopoulos, G.T. Michaltsos, and D.S. Sophianopoulos, "A simplified model for the study of the lateral-torsional vibration of cable-stayed bridges", Proceedings of the Eurodyn 2002, Munich, (2002)

[9] D.Q. Cao, M.T. Song, W.D. Zhu, R.W. Tucker, and C.H.-T. Wang, "Modeling and analysis of the inplane vibration of a complex cable-stayed bridge", J. of Sound and Vibration, (2012), 331(26), pp. 5685-5714

[10] I.G. Raftoyiannis, and G.T. Michaltsos, "Movable anchorage systems for vibration control of stay-cables in bridges",Engineering Structures,(2016),112,pp. 162-171

[11] I.G. Raftoyiannis, and G.T. Michaltsos, "Curvedin-plane cable-stayed bridges. A mathematical model", Int. Journal of Structural Stability and Dynamics, (2012), 12(3), DOI: 10.1142/S0219455412500113

[12] J. Ermopoulos, A. Vlahinos, and Y.-C. Wang, "Stability analysis of cable-stayed bridges", Comp. Structures, (1992), 44(5), pp. 1083-1089

[13] A. Bosdogianni, and D. Olivari, "Wind-reduced and Rain-induced oscillations of cable-stayed bridges", Journal of Wind Eng. and Industrial Aerodynamics, (1997), 64(2-3), pp. 171-185

[14] G.T. Michaltsos, "Stability of a cable-stayed bridge's pylon, under time-depended loading", Collection of papers in memory of Academician P.S. Theocharis. Inst. of Mechanics Problems and Academy of Sciences, Russia, Inst. of Mechanics of Nat. Acad. of Sciences, Armenia, (2005)

[15] G.T. Michaltsos, I.G. Raftoyiannis, and T.G. Konstantakopoulos, "Dynamic Stability of cable-stayed bridge pylons", Int. Journal of Structural Stability and Dynamics, (2008), 8(4), pp. 627-643

[16] Y. Hikami, and N. Shiraishi, "Rain-wind-induced vibrations of cables in cable stayed bridges", Journal of Wind Engineering and Industrial Aerodynamics, (1988), 29(1-3), pp. 409-418

[17] K. Wilde, and W. Witkowski, "Simple model of rain-wind-induced vibrations of stayed cables", Journal of Wind Engineering and Industrial Aerodynamics, (2003), 91(7), pp. 873-891

[18] D. Sophianopoulos, "Rain-wind induced vibrations in stay cables - Response characteristics, excitation mechanism and modeling." Int. Journal of Bridge Engineering, (2013), 1(1), pp. 29-36 